\title{
Treatment of acute Achilles tendon rupture - a multicentre, non-inferiority analysis
}

\author{
Olof Westin ${ }^{1,2^{*}}$ (D), Tony Sjögren ${ }^{1}$, Simon Svedman ${ }^{3}$, Alexandra Horvath ${ }^{4}$, Eric Hamrin Senorski ${ }^{5}$, \\ Kristian Samuelsson ${ }^{1,2}$ and Paul Ackermann ${ }^{6}$
}

\begin{abstract}
Background: While numerous clinical studies have compared the surgical and non-surgical treatment of acute Achilles tendon rupture (ATR), there are no studies that have performed a non-inferiority analysis between treatments.

Methods: Data from patients who were included in five randomised controlled trials from two different centres in Sweden were used. Outcomes at 1 year after ATR consisted of the patient-reported Achilles tendon Total Rupture Score (ATRS) and the functional heel-rise tests reported as the limb symmetry index (LSI). The non-inferiority statistical 10\% margin was calculated as a reflection of a clinically acceptable disadvantage in ATRS and heel-rise outcome when comparing treatments.

Results: A total of 422 patients (350 males and 72 females) aged between 18 and 71 years, with a mean age of 40.6 (standard deviation 8.6), were included. A total of 363 (86\%) patients were treated surgically. The ATRS (difference $(\Delta)=-0.253$ [95\% confidence interval $(\mathrm{Cl}) ;-5.673 ; 5.785] p=0.36$ ) and LSI of heel-rise height (difference $=1.43\left[95 \% \mathrm{Cl}_{;}-2.43 ; 5.59\right] p=0.81$ ), total work (difference $=0.686\left[95 \% \mathrm{Cl}^{\prime}-4.520 ; 6.253\right] p=0.67$ ), concentric power (difference $=2.93[95 \% \mathrm{Cl} ;-6.38 ; 11.90] p=0.063$ ) and repetitions (difference $=-1.30[95 \% \mathrm{Cl}$; $6.32 ; 4.13] p=0.24)$ resulted in non-inferiority within a $\Delta-10 \%$ margin for patients treated non-surgically.

Conclusion: The non-surgical treatment of Achilles tendon ruptures is not inferior compared with that of surgery in terms of 1-year patient-reported and functional outcomes.
\end{abstract}

Keywords: ATRS, Achilles tendon, Rupture, Treatment, Non-surgical, Surgical treatment, Heel-rise test, Rehabilitation

\section{Background}

Rupture to the Achilles tendon is the most prevalent tendon rupture in the lower extremities, with an increasing incidence, which is estimated at approximately 18 injuries annually per 100,000 individuals [1]. Acute Achilles tendon ruptures are particularly common in male recreational athletes and the injury

\footnotetext{
* Correspondence: olof.westin@gmail.com

${ }^{1}$ Department of Orthopaedics, Institute of Clinical Sciences, Sahlgrenska Academy, University of Gothenburg, Gothenburg, Sweden

2Department of Orthopaedics, Sahlgrenska University Hospital, Mölndal, Sweden

Full list of author information is available at the end of the article
}

is associated with persistent deficits in foot and ankle function several years after the initial injury [1]. The general treatment strategy for acute Achilles tendon rupture is either surgical or non-surgical treatment, followed by cast immobilisation or functional bracing and rehabilitation [2]. In spite of this, there is to date no "gold-standard" treatment for Achilles tendon ruptures. While numerous clinical studies compare the two aforementioned treatments, the results are inconsistent with regard to the incidence of complications such as deep venous thrombosis, return to sports and patient-reported outcomes [3]. Several complications, such as infections, adhesion formation, nerve damage

C C The Author(s). 2020 Open Access This article is licensed under a Creative Commons Attribution 4.0 International License, which permits use, sharing, adaptation, distribution and reproduction in any medium or format, as long as you give appropriate credit to the original author(s) and the source, provide a link to the Creative Commons licence, and indicate if changes were made. The images or other third party material in this article are included in the article's Creative Commons licence, unless indicated otherwise in a credit line to the material. If material is not included in the article's Creative Commons licence and your intended use is not permitted by statutory regulation or exceeds the permitted use, you will need to obtain permission directly from the copyright holder. To view a copy of this licence, visit http://creativecommons.org/licenses/by/4.0/. The Creative Commons Public Domain Dedication waiver (http://creativecommons.org/publicdomain/zero/1.0/) applies to the data made available in this article, unless otherwise stated in a credit line to the data. 
and other wound-related complications, are directly related to the surgical treatment of Achilles tendon ruptures [2]. One decisive factor in the selection of treatment is the risk of re-rupturing the Achilles tendon, where surgical treatment has shown a pooled rerupture rate of $3.5 \%$ versus $12.6 \%$ in patients treated non-surgically $[2,4]$.

It has been indicated that patients undergoing surgical treatment for Achilles tendon rupture have superior functional performance in heel-rise tests compared with patients treated non-surgically, possibly owing to a reduced risk of tendon elongation with this treatment [5]. However, there is no study that has used a non-inferiority design to evaluate outcome after treatment in patients who have suffered an acute Achilles tendon rupture.

The advantage of a non-inferior analysis is that it facilitates an understanding of outcomes between two treatments when both are related to benefits and disadvantages. Non-inferior analyses are appropriate if it is possible to demonstrate that one treatment is able to favour outcomes and patients and treating medical professions are willing to sacrifice some degree of benefit in relation to another approved treatment [6]. In terms of this study, a non-inferiority analysis aimed to test whether the outcome of non-surgical treatment was not unacceptably inferior to the outcome of the surgical treatment. This is important, as non-surgical treatment still offers a safer, more cost-effective treatment option, despite having slightly poorer efficacy with regard to a higher incidence of re-rupture and a prolonged time to regain preinjury function compared with the surgical treatment [7]. The non-surgical treatment may therefore still be acceptable due to other advantages if one is willing to sacrifice some degree of benefit relative to the surgical treatment [6].

The purpose of this study was to use non-inferiority analyses to determine whether non-surgical treatment is non-inferior in terms of patient-reported and functional outcomes, compared with surgical treatment after acute Achilles tendon rupture. It was hypothesised that patients in the non-surgical group would not display inferiority in terms of the primary outcomes, the Achilles tendon Total Rupture Score (ATRS) and total work in the heel-rise test, 1 year after the Achilles tendon rupture.

\section{Methods}

\section{Study participants and eligibility criteria}

This study comprised 518 patients who either underwent a surgical or non-surgical treatment following an acute Achilles tendon rupture. Data was collected from five previous randomised controlled trials (RCTs) carried out at two different sites in Sweden; Stockholm and Gothenburg [8-12]. The diagnosis of an Achilles tendon rupture was based upon medical history and clinical examination (tendon palpation and Thompson test). Followingly, patients were randomised regardless of the severity of the rupture. The inclusion and exclusion criteria from the original trials are presented in Table 1. We excluded patients younger than 18 years and those without follow-up outcomes. After applying the exclusion criteria, a total of 422 patients ( 350 males and $72 \mathrm{fe}-$ males) were included in this study.

\section{Follow-up and clinical evaluation}

All the patients were evaluated by experienced physiotherapists 1 year after the surgical or non-surgical treatment of Achilles tendon rupture. The ATRS was used to reflect the patient's perception of Achilles function [14, 16]. The objective evaluation consisted of testing foot and ankle function on both limbs by using a test battery of heel-rise tests to determine concentric power and muscular endurance. Muscular endurance tests consisted of total work, maximum repetitions and heel-rise height. The tests were recorded using a linear encoder with MuscleLab (Ergotest Technology, Oslo, Norway) software. This software is able to record data from different type of sensors connected to the MuscleLab. The testing protocol was conducted as previously described in the literature $[8,15,16]$. All the results were reported as the limb symmetry index (LSI). The LSI reflects relative limb strength or function and is calculated by dividing the test score for the affected limb by that of the healthy limb and multiplying by 100 to obtain side-toside differences expressed as a percentage [16].

\section{Achilles tendon total rupture score}

The ATRS [3] is a patient-reported outcome which is valid, reliable and sensitive for evaluating Achilles function in patients with an Achilles tendon rupture (intraclass correlation coefficient $($ ICC $)=0.96)$ [16]. The ATRS consists of 10 questions, each scored from 0 (worst) to 10 (best), with a maximum total score of 100 . A higher score indicates less physical disability and a higher quality of life [3]. This study used the original version of the ATRS instrument as described by Nilsson-Helander et al. [3].

\section{Heel-rise test: concentric power}

The heel-rise test for concentric power was performed with the patient standing on one leg in a weight machine doing single-leg heel-rises as quickly and forcefully as possible. During this procedure, the knee is not allowed to flex more than $20^{\circ}$ and the procedure is performed in three intervals. The patients started with $13 \mathrm{~kg}$ and an additional $10 \mathrm{~kg}$ was added at each interval until a decrease in power output was recorded. A linear encoder, connected to MuscleLab software, was attached to the shoe and the best trial (i.e. with the highest force in 
Table 1 Cohort description

\begin{tabular}{|c|c|c|c|c|c|c|}
\hline Cohorts & $\begin{array}{l}\text { Included } \\
\text { (n) }\end{array}$ & Inclusions & Exclusions & Surgical treatment & Non-surgical treatment & Rehabilitation \\
\hline $\begin{array}{l}\text { Nilsson- } \\
\text { Helander } \\
\text { et al. [8] } \\
(n=97)\end{array}$ & 88 & $\begin{array}{l}\text { Clinically } \\
\text { verified ATR } \\
\text { which was } \\
\text { treated } \\
\text { within } 72 \mathrm{~h} \text {. }\end{array}$ & $\begin{array}{l}\text { Diabetes mellitus, } \\
\text { previous ATR, other lower } \\
\text { leg injuries, } \\
\text { immunosuppressive } \\
\text { therapy and } \\
\text { neurovascular diseases. }\end{array}$ & $\begin{array}{l}\text { Seventy-nine patients } \\
\text { were treated surgically } \\
\text { using the modified Kessler } \\
\text { suture technique } 8 \text { and } 1- \\
0 \text { PDS. The paratenon was } \\
\text { carefully repaired and the } \\
\text { skin closed with } \\
\text { interrupted nylon sutures. } \\
\text { Post-operatively, the pa- } \\
\text { tients were placed in a } \\
\text { below-the-knee cast with }\end{array}$ & $\begin{array}{l}\text { Fourteen patients were } \\
\text { treated immediately after } \\
\text { randomisation, with a } \\
\text { below-the-knee cast with } \\
\text { the foot in the equinus } \\
\text { position. }\end{array}$ & $\begin{array}{l}\text { All the patients in both } \\
\text { groups were treated with } \\
\text { a below-the-knee cast } \\
\text { with the foot in the equi- } \\
\text { nus position for } 2 \text { weeks, } \\
\text { followed by an adjustable } \\
\text { angle brace by a physio- } \\
\text { therapist for the next } 6 \\
\text { weeks. Weightbearing as } \\
\text { tolerated was allowed } \\
\text { after } 6 \text { to } 8 \text { weeks. }\end{array}$ \\
\hline
\end{tabular}

et al. [9]

$(n=100)$

87 tendon sub-
stance rup-
ture treated
within $96 \mathrm{~h}$.

$\begin{array}{lll}\text { Aufwerber } & 103 & \text { Clinically } \\ \text { et al. [12] } & & \text { verified ATR } \\ (n=150) & & \text { which was } \\ & & \text { treated } \\ & \text { within one } \\ & & \text { week. }\end{array}$

Domeij-

25

et al. [11]

$(n=26)$
Clinically verified closed midtendon sub-

week. which was

treated
Previous ATR, other lower Forty-two patients were leg injuries, neuromuscular diseases, diabetes mellitus, peripheral vascular disease, immunosuppressive treatment and inability to attend follow-up. operated on using the modified Kessler technique. The tendon was repaired end to end using core suturing with two strong semi-

absorbable sutures. No cast was used and the ankle was post-operatively immobilised in a pneumatic walker brace including three heel pads that produce a plantarflexion angle of approximately $22^{\circ}$.

Ongoing anticoagulation treatment, known kidney failure, heart failure with pitting oedema, thrombophlebitis, thromboembolic event during the previous 3 months, known malignancy, haemophilia, pregnancy, other surgery during the previous month, inability to follow instructions and planned follow-up at another hospital.

One hundred and three patients were operated on surgically using the modified Kessler suture technique with two 1-0 polydioxanone (PDS II) sutures. The paratenon and fascia cruris were then sutured separately using 3-0 Vicryl (Ethicon). After surgery the patients were prospectively randomised into two groups, a full-weightbearing and non-weightbearing rehabilitation regime.

Clinically Same as Aufwerber et al. verified ATR [12] within $72 \mathrm{~h}$.

[12]

Forty-five patients were Patients were allowed full treated immediately after weightbearing, which was randomisation, using the encouraged from the first same brace as in the surgical group, including both groups. Early active the three heel pads. rehabilitation started 2 weeks post-operatively and included both range of motion and strength training following a standardised protocol. The surgical group was mobilized in the brace for 6 weeks and the non-surgical group for 8 weeks.

Full-weight-bearing group: after surgery, a walker orthosis with an adjustable angle of motion was used for the next 6 weeks. Functional mobilisation with one-hour daily motion exercise was initiated directly post-operatively.

Non-weight-bearing group: received a conventional non-weight-bearing below-knee plaster cast with the ankle in a $30^{\circ}$ equinus position. At 2 weeks postoperatively, the cast was replaced by a removable walker orthosis with three heel wedges for the remaining 4 weeks of immobilisation. Every consecutive week, a heel wedge was removed. At 6 weeks, all patients discontinued immobilization.

All patients received a below-knee plaster cast with the ankle in $30^{\circ}$ equinus in the outpatient clinic shortly after the completion of surgery, and were non-weight-bearing with crutches during the first 2 weeks.

The intervention group received intermittent pneumatic compression applied to the foot under the plaster cast, which was discontinued at 2 weeks post-operatively. At the 2-week visit all patients received a lower leg orthosis and were instructed to start full weightbearing. The orthotic treatment was discontinued at 6 weeks post-operatively. 
Table 1 Cohort description (Continued)

\begin{tabular}{|c|c|c|c|c|c|}
\hline Cohorts & $\begin{array}{l}\text { Included } \\
\text { (n) }\end{array}$ & Inclusions & Exclusions & Surgical treatment & Non-surgical treatment \\
\hline $\begin{array}{l}\text { Domeij- } \\
\text { Arverud } \\
\text { et al. [10] } \\
(n=150)\end{array}$ & 119 & $\begin{array}{l}\text { Clinically } \\
\text { verified ATR } \\
\text { which was } \\
\text { treated } \\
\text { within } 96 \mathrm{~h} .\end{array}$ & $\begin{array}{l}\text { Same as Aufwerber et al. } \\
\text { [12] }\end{array}$ & $\begin{array}{l}\text { One hundred and } \\
\text { nineteen patients were } \\
\text { operated surgically using } \\
\text { the same techniques as } \\
\text { Valkering et al. [13] } \\
\text { After surgery the patients } \\
\text { were prospectively } \\
\text { randomised into two } \\
\text { groups both groups non- } \\
\text { weight-bearing, but the } \\
\text { intervention group re- } \\
\text { ceived adjuvant calf inter- } \\
\text { mittent pneumatic } \\
\text { compression. }\end{array}$ & $\begin{array}{l}\text { Control group: The patients received a below-knee } \\
\text { plaster cast applied in the outpatient clinic shortly } \\
\text { after the completion of surgery, with the ankle } \\
\text { plantar-flexed to provide } 30^{\circ} \text { of equinus. Patients } \\
\text { were non-weight-bearing during the first } 2 \text { post- } \\
\text { operative weeks and were given crutches. } \\
\text { Intervention group: The intervention group received } \\
\text { intermittent pneumatic compression applied to the } \\
\text { calf beneath a walker orthosis. At } 2 \text { weeks post- } \\
\text { operatively the intervention was discontinued. } \\
\text { At the 2-week visit all patients received a lower leg } \\
\text { orthosis and were instructed to start full weight- } \\
\text { bearing. The orthotic treatment was discontinued at } \\
6 \text { weeks post-operatively. }\end{array}$ \\
\hline
\end{tabular}

Clinically verified Achilles tendon rupture (ATR): presenting with symptoms including sudden increase in pain around the Achilles, weakness and poor balance and limited walking distance [14] and a palpable gap in the tendon and a positive Thompson test [15]

$P D S$ - polydioxanone

watts (W)) for each weight was recorded and used for analysis. This was calculated by entering the weight of the patient and the extra external weight into the MuscleLab software for which peak power was calculated for each weight interval. For the patients included from the cohorts of Domeij-Arverud [10,11] the heelrise test for concentric power was performed without adding extra weight [17].

\section{Heel-rise test: total work, maximum repetitions and height}

The heel-rise test reflects the function of the plantar flexors of the lower limb and was evaluated by assessing single-leg height, repetitions and total work (in joules (J)). The uninjured limb was always tested first. The test was performed with the patient standing on a $20 \mathrm{~cm}$ flat box with a tilted wedge $\left(10^{\circ}\right)$. The patients were instructed to go as high as possible on each heel rise and perform as many heel rises as possible, while a metronome was used to keep the frequency at 30 heel rises a minute. The test was terminated when the patient was unable to maintain the frequency or did not perform a correct heel rise (minimum $2 \mathrm{~cm}$ ). A linear encoder (MuscleLab) was used to measure the aforementioned outcomes. With regard to the heel-rise height, the maximum height achieved by the patient was recorded for data analysis. To obtain the values for total work, this was calculated as body weight $\mathrm{x}$ total distance in $\mathrm{J}$.

\section{Statistical analysis}

All the statistical analyses were performed using the Statistical Analysis System (SAS, SAS institute Inc., NC, USA). Continuous variables were described as the mean (standard deviation (SD)), median (minimum and maximum) and categorical variables with count (n) and proportions (\%).
The heel-rise tests and ATRS were compared between the two treatment groups with the Mann-Whitney Utest and reported with $p$-values and confidence intervals (CI). To calculate confidence intervals for the continuous variables, bootstrapping of 1000 replicated picking the 2.5 and 97.5 percentiles of the 10,000 mean differences was used. To determine non-inferiority, we hypothesised that non-surgical treatment would not be inferior to surgical treatment by delta- $\Delta$ margin (difference between groups) for the ATRS \pm 10 points and LSI $\pm 10 \%$ which have been clinically accepted as noninferiority and preclude equality by using a T-test, $95 \%$ $\mathrm{CI}$ and $p$-value. The minimal clinical important difference (MCID) of ATRS has been stated as 10 points which equals $10 \%$ of the total score (100 points) and is in line with previous literature on the topic [3]. At the 1year follow-up, confounders adjusted for were age, sex, body mass index (BMI) defined as $\left(\mathrm{kg} / \mathrm{m}^{2}\right)$ and smoking (yes/no). All testing was performed at a $5 \%$ significance level.

\section{Results}

In the present study, 422 patients were included, whereof 363 were treated surgically and 59 nonsurgically. The patients were between 18 and 71 years of age, with a mean age of 40.6 (SD 8.6). The mean BMI of the included patients was 26.1 (SD 3.3) and 95.2\% were non-smokers. Demographic differences between patients that received surgical and non-surgical treatment are presented in Table 2. A larger proportion of males were treated surgically $(85.1 \%)$ compared with females (69.5\%) $(p=0.0031)$. In addition, there was a larger number of males in the cohort compared with females, 350 (82.9\%) versus $72(17.1 \%)$ respectively. This discrepancy between sexes also resulted in significant differences in the mean height $(p=0.0044)$ and weight $(p=0.0024)$ of the patients for the two treatments. Nevertheless, there were 
Table 2 Patient baseline characteristics

\begin{tabular}{|c|c|c|c|c|}
\hline Demographics & $\begin{array}{l}\text { Total included cohort } \\
(\boldsymbol{n}=422)\end{array}$ & $\begin{array}{l}\text { Surgical treatment } \\
(\boldsymbol{n}=363)\end{array}$ & $\begin{array}{l}\text { Non-surgical treatment } \\
(\boldsymbol{n}=59)\end{array}$ & $p$-value \\
\hline \multicolumn{5}{|l|}{ Patient sex } \\
\hline Males & $350(82.9 \%)$ & $309(85.1 \%)$ & $41(69.5 \%)$ & \\
\hline Females & $72(17.1 \%)$ & $54(14.9 \%)$ & $18(30.5 \%)$ & 0.0031 \\
\hline Age (years) & $\begin{array}{l}40.6(8.6) \\
40.0(18.0 ; 71.0) \\
n=422\end{array}$ & $\begin{array}{l}40.4(8.4) \\
39.0(18.0 ; 71.0) \\
n=363\end{array}$ & $\begin{array}{l}41.7(9.6) \\
41.0(21.0 ; 64.0) \\
n=59\end{array}$ & 0.33 \\
\hline Height $(\mathrm{cm})$ & $\begin{array}{l}178.3(8.7) \\
180.0(144.0 ; 200.0) \\
n=412\end{array}$ & $\begin{array}{l}178.8(8.4) \\
180.0(144.0 ; 200.0) \\
n=354\end{array}$ & $\begin{array}{l}175.1(9.7) \\
175.5(153.0 ; 195.0) \\
n=58\end{array}$ & 0.0044 \\
\hline Weight (kg) & $\begin{array}{l}83.1(13.2) \\
83.0(43.0 ; 129.0) \\
n=413\end{array}$ & $\begin{array}{l}83.8(13.1) \\
84.0(43.0 ; 129.0) \\
n=355\end{array}$ & $\begin{array}{l}78.4(12.7) \\
75.0(57.0 ; 112.0) \\
n=58\end{array}$ & 0.0024 \\
\hline $\mathrm{BMI}\left(\mathrm{kg} / \mathrm{m}^{2}\right)$ & $\begin{array}{l}26.1(3.3) \\
25.7(19.6 ; 43.6) \\
n=412\end{array}$ & $\begin{array}{l}26.1(3.3) \\
25.7(19.6 ; 43.6) \\
n=354\end{array}$ & $\begin{array}{l}25.5(3.2) \\
24.6(20.1 ; 38.9) \\
n=58\end{array}$ & 0.060 \\
\hline \multicolumn{5}{|l|}{ Smoking } \\
\hline Non-smoker & $316(95.2 \%)$ & $275(95.8 \%)$ & $41(91.1 \%)$ & \\
\hline Smoker & $16(4.8 \%)$ & $12(4.2 \%)$ & $4(8.9 \%)$ & 0.17 \\
\hline \multicolumn{5}{|l|}{ Study } \\
\hline Nilson-Helander et al. [8] $\quad(n=97)$ & $88(20.9 \%)$ & $74(20.4 \%)$ & $14(23.7 \%)$ & \\
\hline Olsson et al. [9] $(n=100)$ & $87(20.6 \%)$ & $42(11.6 \%)$ & $45(76.3 \%)$ & \\
\hline Aufwerber et al. [12] $(n=150)$ & $103(24.4 \%)$ & $103(28.3 \%)$ & 0 & \\
\hline Domeij-Arverud et al. [11] $(n=26)$ & $25(5.9 \%)$ & $25(6.9 \%)$ & 0 & \\
\hline Domeij-Arverud et al. [10] $(n=150)$ & 119 (28.2\%) & $119(32.8 \%)$ & 0 & \\
\hline
\end{tabular}

For categorical variables, $n(\%)$ is presented. For continuous variables, the mean (standard deviation $(S D)) /$ median $(\min ; \max ) / n=$ is presented $B M I$ Body mass index

no differences in BMI $(p=0.060)$, age $(p=0.33)$ and smoking ( $p=0.17)$ between the two treatment options. The prevalence of smoking was rare, with only 16 patients being smokers, and, of these, the majority were treated surgically, 12 versus four in the non-surgical group.

\section{Achilles tendon rupture score}

In terms of the ATRS, the mean for both groups at 1 year was 81.5 (SD 18.6) points. The surgically treated patients scored 81.5 (SD 18.2) compared with 81.7 (SD 21.4) for the non-surgical group (difference $=-0.25[95 \% \mathrm{CI}$; 5.67; 5.79] $p=0.36$ ) (Table 3;Fig. 1).

\section{Maximum heel-rise height}

The 1-year limb symmetry index (LSI) for heel-rise height was a mean of $80.7 \%$ (SD 15.3). The LSI for heel-rise height did not differ between groups. The surgically treated group had a mean LSI for heel-rise height of $80.9 \%$, while the non-surgical group had $79.5 \%($ difference $=1.43[95 \% \mathrm{CI} ;-2.43 ; 5.59] p=0.81)$ (Table 3;Fig. 1).

\section{Heel-rise total work}

The mean LSI for heel-rise total work at the 1-year follow-up was 73.3\% (SD 25.3). There was no difference between the surgical and non-surgical treatment groups in the 1-year LSI for heel-rise total work. The mean for the surgically treated patients was $73.4 \%$, while it was $72.7 \%$ for the non-surgical group (difference $=0.686$ [95\% CI; - 4.520; 6.253] $p=0.67$ ) (Table 3;Fig. 1).

\section{Heel-rise concentric power}

The mean 1-year LSI for heel-rise concentric power was $85.0 \%$ (SD 27.1). There was no difference in the mean values for the LSI of heel-rise concentric power in patients treated surgically or non-surgically. The mean LSI of heel-rise concentric power was $85.4 \%$ for surgically treated patients and $82.5 \%$ for the non-surgical group (difference $=2.93 \quad[95 \% \quad \mathrm{CI} ;-6.38 ; 11.90] \quad p=0.063$ ) (Table 3;Fig. 1).

\section{Heel-rise repetitions}

The mean 1-year LSI for heel-rise repetitions was $90.3 \%$ (SD 23.6). For the surgically treated patients, the mean was $90.1 \%$, while it was $91.4 \%$ for the non-surgical group, which did not differ between the treatment 
Table 3 Results of 12-month postinjury evaluation

\begin{tabular}{|c|c|c|c|c|c|}
\hline Outcome & $\begin{array}{l}\text { Total } \\
(\boldsymbol{n}=422)\end{array}$ & $\begin{array}{l}\text { Surgical treatment } \\
(\boldsymbol{n}=363)\end{array}$ & $\begin{array}{l}\text { Non-surgical treatment } \\
(\boldsymbol{n}=59)\end{array}$ & $p$-value & $\begin{array}{l}\text { Difference between groups } \\
\text { Mean }(95 \% \mathrm{Cl})\end{array}$ \\
\hline Achilles Tendon Rupture Score & $\begin{array}{l}81.5(18.6) \\
87.0(0.0 ; 100.0) \\
n=399\end{array}$ & $\begin{array}{l}81.5(18.2) \\
87.0(0.0 ; 100.0) \\
n=340\end{array}$ & $\begin{array}{l}81.7(21.4) \\
91.0(2.0 ; 100.0) \\
n=59\end{array}$ & 0.36 & $-0.253(-5.673 ; 5.785)$ \\
\hline LSI - maximum height & $\begin{array}{l}80.7(15.3) \\
81.1(28.0 ; 139.3) \\
n=397\end{array}$ & $\begin{array}{l}80.9(15.5) \\
81.3(33.6 ; 139.3) \\
n=338\end{array}$ & $\begin{array}{l}79.5(14.4) \\
79.6(28.0 ; 105.0) \\
n=59\end{array}$ & 0.81 & $1.43(-2.43 ; 5.59)$ \\
\hline LSI - total work & $\begin{array}{l}73.3(25.3) \\
73.2(7.0 ; 288.0) \\
n=396\end{array}$ & $\begin{array}{l}73.4(26.4) \\
73.1(7.0 ; 288.0) \\
n=337\end{array}$ & $\begin{array}{l}72.7(18.2) \\
75.0(7.0 ; 111.4) \\
n=59\end{array}$ & 0.67 & $0.686(-4.520 ; 6.253)$ \\
\hline LSI - concentric power & $\begin{array}{l}85.0(27.1) \\
80.6(24.6 ; 216.0) \\
n=390\end{array}$ & $\begin{array}{l}85.4(25.7) \\
82.0(24.6 ; 200.0) \\
n=332\end{array}$ & $\begin{array}{l}82.5(34.1) \\
72.9(34.0 ; 216.0) \\
n=58\end{array}$ & 0.063 & $2.93(-6.38 ; 11.90)$ \\
\hline LSI - repetitions & $\begin{array}{l}90.3(23.6) \\
90.2(13.3 ; 275.0) \\
n=397\end{array}$ & $\begin{array}{l}90.1(24.5) \\
89.2(13.3 ; 275.0) \\
n=338\end{array}$ & $\begin{array}{l}91.4(17.9) \\
92.0(26.0 ; 139.4) \\
n=59\end{array}$ & 0.24 & $-1.30(-6.32 ; 4.13)$ \\
\hline
\end{tabular}

For continuous variables, the mean (standard deviation)/median ( $\min ; \mathrm{max}) / n=$ is presented CI Confidence Interval, LSI Limb Symmetry Index

groups (difference $=-1.30[95 \% \mathrm{CI} ;-6.32 ; 4.13] p=$ 0.24) (Table 3;Fig. 1).

\section{Discussion}

This randomised, non-inferior study based on a pooled sample of 422 patients is the first investigation to demonstrate that non-surgical treatment is non-inferior to surgical treatment 1 year after Achilles tendon rupture with regard to the ATRS and LSI in the heel-rise tests for concentric power, heel-rise height, total work and heel-rise repetitions.

The non-inferior evaluation made it possible to encourage risk-benefit assessments and safety advantages that resulted in a marginal, clinically acceptable loss of efficacy in heel rise and ATRS. The results of this study may help when deciding on the treatment method after Achilles tendon rupture and, ultimately, adverse complications related to surgical treatment could potentially be avoided $[4,18]$. For this reason, the present study confirms that non-surgical treatment is an acceptable alternative for the treatment of acute Achilles tendon rupture in terms of functional outcome and ATRS. This is in line with previous findings indicating that surgical treatment does not necessarily produce a superior outcome in terms of strength and range of motion in comparison with non-surgical treatment [19].

The findings in this study suggest non-inferiority using the fixed-margin method, calculating the lower limit of 95\% CI difference between treatments. Conclusions can be drawn if the CI lies within the margin of delta- $\Delta$. To preserve viability, our fixed (delta- $\Delta$ ) margin was set at $10 \%$, a narrow margin determined by a Delphi-type approach [20]. The delta- $\Delta$ is determined by statistical and clinical judgement, i.e. asking orthopaedic surgeons and physiotherapists how much benefit over side-effects they are willing to forego by using non-surgical treatment. In order not to depend completely on the empiricism of investigators and the expectations of the medical community, the ATRS was used in the non-inferior analysis to incorporate patients' perceptions of treatment outcome. The ATRS is an important outcome tool, which enables the creation of an acceptable margin based on anticipated benefits and risks. The results suggest noninferiority that approaches equivalence for the ATRS at the 1-year follow-up, similar to that found in other studies, indicating that no difference exists with regard to the ATRS between patients undergoing surgical and non-surgical treatment $[8,9,21]$. This outcome suggests that restrictions caused by symptoms in physical activity and everyday living are not inferior in non-surgically treated Achilles tendon rupture patients as opposed to those treated surgically.

Our results further demonstrate that maximum heelrise height is non-inferior for patients treated nonsurgically, which is in line with the results of previous studies [22-25]. A reduction in the maximum heel-rise height performance has been associated with tendon elongation, creating abnormalities in power generation around the ankle and in gait [5, 26]. A meta-analysis by Jiang et al. [27] comprising 894 patients revealed no difference in tendon elongation outcome between nonsurgical and surgical treatment after Achilles tendon rupture. Nevertheless, it is important to acknowledge that recent studies have associated tendon elongation preceding poor maximum heel-rise performance with potentially faulty rehabilitation [28]. Erroneous rehabilitation may be produced by overstraining the tendon and the degree of tendon end separation in non-surgical treatment. For this reason, the non-surgical treatment of Achilles tendon ruptures requires an effective 


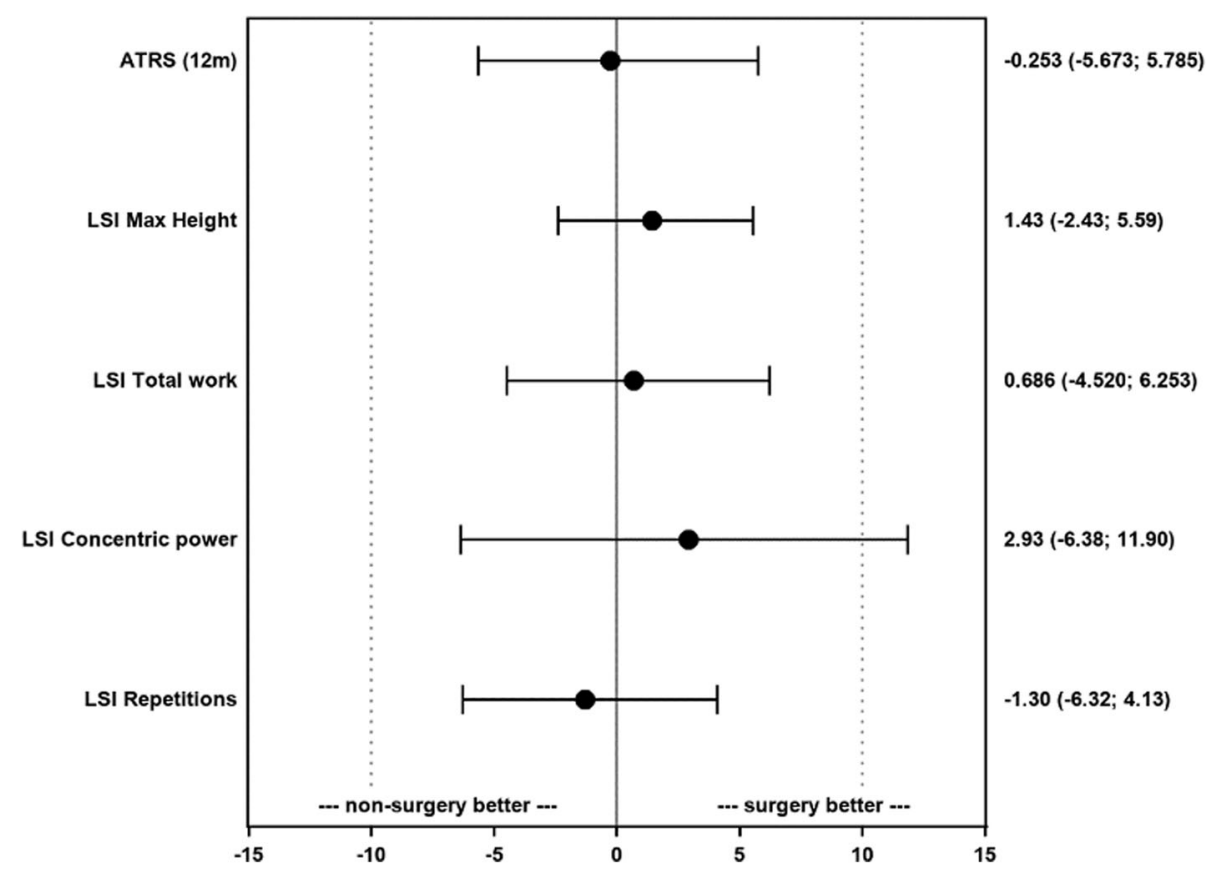

Fig. 1 Non-inferior analysis comparing non-surgical treatment with surgical treatment. Non-inferior margin: $\pm 10 \% \Delta$. ATRS: Achilles tendon rupture score. LSI: Limb symmetry index. Numbers present: difference, 95\% confidence intervals

rehabilitation plan and implementation. The cause and effect of tendon elongation have, however, not been established. In addition, outcomes of tendon elongation measurements are not consistent between different methods $[29,30]$.

Traditional rehabilitation protocols involved the usage of a below-knee non-weight bearing rigid cast for 6 weeks, followed by mobilization of the ankle joint and strengthening exercises [31]. However, this rehabilitation regimen has been questioned as recent investigations have demonstrated that functional rehabilitation including postoperative early weightbearing combined with early ankle motion exercises are associated with earlier return to sport, increased patient satisfaction and reduced tendon elongation when compared with traditional rehabilitation protocols [32-34]. This demonstrate that the type of rehabilitation and onset of load is imperative and can moderate effectiveness of treatment following the initial treatment of ATR. In general, all patients in our cohort that were surgically treated discontinued with a walker orthosis after 6 weeks postoperative, while the non-surgically treated patients discontinued their walker orthosis at 8 weeks postoperative. In some of the trials, the rehabilitation within the first 2 weeks differed, although this had little effect on the postoperative outcome including the ATRS and function heel-rise tests.

The 1-year results for concentric power recorded during heel-rise evaluation resulted in a confidence interval of $(\mathrm{CI} ;-6.38 ; 11.90)$. The lower margin of the confidence interval is above the lower $\Delta$-margin but exceeds the upper $\Delta$-margin (10\%) non-significantly in favour of surgical treatment. This is in agreement with a metaanalysis by Ke Zouh et al. [35] which reported comparable numbers when comparing surgical with nonsurgical treatment with regard to concentric power $(\mathrm{CI}$; $-2.59 ; 17.06, p=0.15)$ [35]. This finding is, however, contradicted by one of our included cohorts [8]. NilssonHelander et al. [8] presented significantly superior results for heel-rise concentric power at the 6-month follow-up for patients treated surgically. Nevertheless, there is still a significant decrease in function relative to the uninjured leg in the included cohorts [8].

Herein, we demonstrate that the heel-rise test for total work and repetitions resulted in non-inferiority for the non-surgical treatment. A randomised controlled trial comprising 80 patients allocated to non-surgical and surgical treatment found no significant differences in total work and repetitions at the 12-month follow-up [36]. In contrast, Lantto et al. [37] reported that plantar flexion strength is about $10 \%$ less for patients treated non-surgically, while another trial found significantly higher plantar flexion strength in patients undergoing non-surgical treatment [38]. It is important to be aware that heel-rise work and repetition reflect muscular strength and endurance and may vary due to individual variations in muscle mass, body habitus, patients' physical condition prior to injury and the way patients 
pursue their former physical activity and not the initial treatment itself. A reduction in plantar flexion strength may not be clinically relevant for most patients, but it is still a common argument that is used to endorse the fact that surgery should be considered for athletic patients with an Achilles tendon rupture. This argument has, however, been challenged by studies of National Basketball Association and National Football League players in which the majority of players did not regain their preinjury level performance or were unable to return to sport following surgical Achilles tendon repair [38, 39].

Furthermore, controversy exists regarding the best treatment strategy for acute Achilles tendon rupture and whether adverse events such as deep venous thrombosis are comparable between treatments. Decreased rerupture rates after surgical treatment have been the main argument in promoting surgery as the primary treatment option compared with non-surgical treatment [40], as the former treatment approach results in a rerupture rate of $3.5 \%$ and the latter in a rate of $12.6 \%$ with a pooled relative risk of 0.27 (95\% CI; $0.11 ; 0.64)$ [4]. However, a meta-analysis pertaining to the outcomes following surgical and non-surgical treatment of ATR indicated that, when early range of motion was incorporated in the treatment regimen, there was no difference in the re-rupture risk between the two treatments [41]. As a result, an effective rehabilitation protocol for Achilles tendon rupture appears to be more important than the surgical treatment method itself. In addition, surgical repair involves, but is not limited to, an increased risk of infection, adhesions and disturbed skin sensibility with a pooled relative risk of 10.6 (95\% CI; 4.8;23.3) as compared with non-surgical treatment [4]. Damage to the sural nerve during surgical repair of an ATR has also been associated with increased risk of postoperative pain and reduced function [18]. Moreover, a recent investigation of direct health-care costs and indirect costs (sick leave days) showed that surgical treatment was more expensive compared with non-surgical treatment [7].

The complications and benefits reported after both surgical and non-surgical treatments indicate that there is an intricate relationship between patient-related factors and treatment approach. Our results extend previous knowledge, suggesting non-inferiority for non-surgical treatment in evaluations of heel-rise performance and ATRS. Non-surgical treatment with an appropriate rehabilitation strategy may result in acceptable functional outcome, re-rupture risk and lower general costs, without the risk of wound complications. Including the patients' preferences and expectations in relation to clinical outcome is therefore imperative when deciding on treatment approach. Patient compliance is, however, critical to the success of non-surgical interventions and larger high-quality multicentre studies are required to determine the optimal treatment $[42,43]$.

\section{Limitations of this study}

Considering the nature of and the differences between non-surgical and surgical treatment options for acute Achilles tendon rupture, the blinding of investigators, participants and outcome assessors was not practicable when personnel needed to observe participants in the follow-up process. Potentially influencing imprecise endpoint ascertainment, as well as non-blinded patients, may have influenced their behaviour and response to outcome, thereby generating performance bias [44]. However, primary outcome was also assessed by a patient-questionnaire (ATRS) as primary evidence of valuable life-functional restrictions and pain. This could increase the magnitude of detection bias, because patient estimations are a subjective measurement [45]. Nevertheless, the ATRS outcome tool in our study is similar to that in other studies comparing alternative treatments $[8,9,21]$.

The number of patients included in the non-surgical treatment group was limited to 59 compared with 363 who were treated surgically. The unevenly distributed number of patients might have had an impact on the analysis, with a substantial effect size in the evaluation of functional outcome that may bias the overall results as compared with treatment. However, the two treatment groups were comparable with regard to demographic characteristics including age and BMI. Despite the uneven number of patients, surprisingly good results were obtained in relation to heel-rise repetitions after nonsurgical treatment compared with surgical treatment. Finally, the cohorts used in this study had different treatment interventions regarding surgical technique, exclusion criteria and rehabilitation regimen. This may have created an imbalance in treatment adherence and may have impacted the overall consistency, especially as the non-surgical treatment group consisted of a small study sample.

\section{Conclusion}

The non-surgical treatment of Achilles tendon ruptures is non-inferior compared with surgery at 1 year in terms of the ATRS and LSI for heel-rise height, total work, repetitions and concentric power.

\section{Abbreviations \\ ATR: Achilles Tendon Rupture; ATRS: Achilles Tendon Total Rupture Score; BMI: Body Mass Index; Cl: Confidence Interval; ICC: Intraclass Correlation Coefficient; J: Joule; LSI: Limb Symmetry Index; RCT: Randomised Controlled Trial; SD: Standard Deviation; W: Watt}

\section{Acknowledgements}

The authors thank biostatisticians Bengt Bengtsson and Nils-Gunnar Pehrsson from Statistiska Konsultgruppen for help with statistical analyses and advice in regard to interpretation of data. 


\section{Authors' contributions}

Authors OW, TS and EHS contributed substantially to the interpreting of the statistical analyses and are responsible of drafting the work and revising it critically for important intellectual content. Authors SS, AH, KS and PA have done large contributions to revise the manuscript. All the authors have read the final manuscript and given their final approval for the manuscript to be published. Furthermore, all the authors agree to be accountable for all the aspects of the research in ensuring that questions related to the accuracy or integrity of any part of the work are appropriately investigated and resolved.

\section{Funding}

No specific funding was received for this research from any funding agency in the public, commercial or not-for-profit sectors. Open access funding provided by University of Gothenburg.

\section{Availability of data and materials}

The datasets used and/or analysed during the current study are available from the corresponding author on reasonable request.

\section{Ethics approval and consent to participate}

Ethical approval for this study was obtained from the regional ethics review boards in Gothenburg and Stockholm.

\section{Consent for publication}

Not applicable.

\section{Competing interests}

The authors declare that they have no potential conflicts of interest. The original datasets of the included randomised control trials can be accessed by contacting the corresponding author.

\section{Author details}

'Department of Orthopaedics, Institute of Clinical Sciences, Sahlgrenska Academy, University of Gothenburg, Gothenburg, Sweden. ${ }^{2}$ Department of Orthopaedics, Sahlgrenska University Hospital, Mölndal, Sweden. ${ }^{3}$ Integrative Orthopedic Laboratory, Department of Molecular Medicine and Surgery, Karolinska Institutet, Stockholm, Sweden. ${ }^{4}$ Department of Internal Medicine and Clinical Nutrition, Institute of Medicine, Sahlgrenska Academy, University of Gothenburg, Gothenburg, Sweden. ${ }^{5}$ Department of Health and Rehabilitation, Institute of Neuroscience and Physiology, Sahlgrenska Academy, University of Gothenburg, Gothenburg, Sweden. ${ }^{6}$ Department of Orthopedic Surgery, Karolinska University Hospital, Stockholm, Sweden.

\section{Received: 2 March 2020 Accepted: 28 April 2020}

\section{Published online: 08 June 2020}

\section{References}

1. Gulati V, Jaggard M, Al-Nammari SS, Uzoigwe C, Gulati P, Ismail N, et al. Management of achilles tendon injury: a current concepts systematic review. World J Orthop. 2015;6(4):380-6

2. Yang X, Meng H, Quan Q, Peng J, Lu S, Wang A. Management of acute Achilles tendon ruptures: a review. Bone Joint Res. 2018;7(10):561-9.

3. Nilsson-Helander K, Thomee R, Silbernagel KG, Thomee P, Faxen E, Eriksson $\mathrm{Bl}$, et al. The Achilles tendon Total rupture score (ATRS): development and validation. Am J Sports Med. 2007:35(3):421-6.

4. Khan RJ, Fick D, Keogh A, Crawford J, Brammar T, Parker M. Treatment of acute achilles tendon ruptures. A meta-analysis of randomized, controlled trials. J Bone Joint Surg Am. 2005;87(10):2202-10.

5. Silbernagel KG, Steele R, Manal K. Deficits in heel-rise height and achilles tendon elongation occur in patients recovering from an Achilles tendon rupture. Am J Sports Med. 2012;40(7):1564-71.

6. Schumi J, Wittes JT. Through the looking glass: understanding noninferiority. Trials. 2011;12:106

7. Westin O, Svensson M, Nilsson Helander K, Samuelsson K, Gravare Silbernagel $\mathrm{K}$, Olsson $\mathrm{N}$, et al. Cost-effectiveness analysis of surgical versus non-surgical management of acute Achilles tendon ruptures. Knee Surg Sports Traumatol Arthrosc. 2018;26(10):3074-82.

8. Nilsson-Helander K, Silbernagel KG, Thomee R, Faxen E, Olsson N, Eriksson $\mathrm{Bl}$, et al. Acute achilles tendon rupture: a randomized, controlled study comparing surgical and nonsurgical treatments using validated outcome measures. Am J Sports Med. 2010;38(11):2186-93.
9. Olsson N, Silbernagel KG, Eriksson BI, Sansone M, Brorsson A, NilssonHelander K, et al. Stable surgical repair with accelerated rehabilitation versus nonsurgical treatment for acute Achilles tendon ruptures: a randomized controlled study. Am J Sports Med. 2013:41(12):2867-76.

10. Domeij-Arverud E, Labruto F, Latifi A, Nilsson G, Edman G, Ackermann PW. Intermittent pneumatic compression reduces the risk of deep vein thrombosis during post-operative lower limb immobilisation: a prospective randomised trial of acute ruptures of the Achilles tendon. Bone Joint J. 2015:97-b(5):675-80

11. Domeij-Arverud E, Latifi A, Labruto F, Nilsson G, Ackermann PW. Can foot compression under a plaster cast prevent deep-vein thrombosis during lower limb immobilisation? Bone Joint J. 2013;95-b(9):1227-31.

12. Aufwerber $S$, Heijne A, Edman G, Grävare Silbernagel K, Ackermann PW. Early mobilization does not reduce the risk of deep venous thrombosis after Achilles tendon rupture: a randomized controlled trial. Knee Surg Sports Traumatol Arthrosc. 2020;28(1):312-9.

13. Valkering KP, Aufwerber S, Ranuccio F, Lunini E, Edman G, Ackermann PW. Functional weight-bearing mobilization after Achilles tendon rupture enhances early healing response: a single-blinded randomized controlled trial. Knee Surg Sports Traumatol Arthrosc. 2017;25(6):1807-16.

14. Silbernagel KG, Brorsson A, Olsson N, Eriksson Bl, Karlsson J, NilssonHelander K. Sex differences in outcome after an acute Achilles tendon rupture. Orthop J Sports Med. 2015;3(6):2325967115586768.

15. Silbernagel KG, Gustavsson A, Thomee R, Karlsson J. Evaluation of lower leg function in patients with Achilles tendinopathy. Knee Surg Sports Traumatol Arthrosc. 2006;14(11):1207-17.

16. Silbernagel KG, Nilsson-Helander K, Thomee R, Eriksson BI, Karlsson J. A new measurement of heel-rise endurance with the ability to detect functional deficits in patients with Achilles tendon rupture. Knee Surg Sports Traumatol Arthrosc. 2010;18(2):258-64.

17. Arverud ED, Anundsson P, Hardell E, Barreng G, Edman G, Latifi A, et al. Ageing, deep vein thrombosis and male gender predict poor outcome after acute Achilles tendon rupture. Bone Joint J. 2016;98-B(12):1635-41.

18. Majewski M, Rohrbach M, Czaja S, Ochsner P. Avoiding sural nerve injuries during percutaneous Achilles tendon repair. Am J Sports Med. 2006;34(5): 793-8.

19. Willits $K$, Amendola A, Bryant $D$, Mohtadi NG, Giffin JR, Fowler $P$, et al. Operative versus nonoperative treatment of acute Achilles tendon ruptures: a multicenter randomized trial using accelerated functional rehabilitation. J Bone Joint Surg Am. 2010;92(17):2767-75.

20. McMillan SS, King M, Tully MP. How to use the nominal group and Delphi techniques. Int J Clin Pharm. 2016;38(3):655-62.

21. Lim CS, Lees D, Gwynne-Jones DP. Functional outcome of acute Achilles tendon rupture with and without operative treatment using identical functional bracing protocol. Foot Ankle Int. 2017;38(12):1331-6.

22. Schepull T, Kvist J, Aspenberg P. Early E-modulus of healing Achilles tendons correlates with late function: similar results with or without surgery. Scand J Med Sci Sports. 2012;22(1):18-23.

23. Mortensen HM, Skov O, Jensen PE. Early motion of the ankle after operative treatment of a rupture of the Achilles tendon. A prospective, randomized clinical and radiographic study. J Bone Joint Surg Am. 1999;81(7):983-90.

24. Kangas J, Pajala A, Ohtonen P, Leppilahti J. Achilles tendon elongation after rupture repair: a randomized comparison of 2 postoperative regimens. Am J Sports Med. 2007;35(1):59-64.

25. Brorsson A, Willy RW, Tranberg R, Gravare SK. Heel-rise height deficit 1 year after Achilles tendon rupture relates to changes in ankle biomechanics 6 years after injury. Am J Sports Med. 2017:45(13):3060-8.

26. Don R, Ranavolo A, Cacchio A, Serrao M, Costabile F, lachelli M, et al. Relationship between recovery of calf-muscle biomechanical properties and gait pattern following surgery for achilles tendon rupture, Clin Biomech (Bristol, Avon). 2007:22(2):211-20.

27. Jiang N, Wang B, Chen A, Dong F, Yu B. Operative versus nonoperative treatment for acute Achilles tendon rupture: a meta-analysis based on current evidence. Int Orthop. 2012;36(4):765-73.

28. Eliasson P, Agergaard AS, Couppe C, Svensson R, Hoeffner R, Warming S, et al. The ruptured Achilles tendon elongates for 6 months after surgical repair regardless of early or late Weightbearing in combination with ankle mobilization: a randomized clinical trial. Am J Sports Med. 2018:46(10):2492502.

29. Westin O, Nilsson Helander K, Gravare Silbernagel K, Moller M, Kalebo P, Karlsson J. Acute ultrasonography investigation to predict Reruptures and 
outcomes in patients with an Achilles tendon rupture. Orthop I Sports Med. 2016;4(10):2325967116667920.

30. Karlsson J, Calder JDF, CNv D, Maffulli N, Thermann H. Achilles tendon disorders : a comprehensive overview of diagnosis and treatment; 2014.

31. Zhao JG, Meng XH, Liu L, Zeng XT, Kan SL. Early functional rehabilitation versus traditional immobilization for surgical Achilles tendon repair after acute rupture: a systematic review of overlapping meta-analyses. Sci Rep. 2017;7:39871.

32. Brumann M, Baumbach SF, Mutschler W, Polzer H. Accelerated rehabilitation following Achilles tendon repair after acute rupture - development of an evidence-based treatment protocol. Injury. 2014;45(11):1782-90.

33. Mark-Christensen T, Troelsen A, Kallemose T, Barfod KW. Functional rehabilitation of patients with acute Achilles tendon rupture: a metaanalysis of current evidence. Knee Surg Sports Traumatol Arthrosc. 2016; 24(6):1852-9.

34. Huang J, Wang C, Ma X, Wang X, Zhang C, Chen L. Rehabilitation regimen after surgical treatment of acute Achilles tendon ruptures: a systematic review with meta-analysis. Am J Sports Med. 2015;43(4):1008-16.

35. Zhou K, Song L, Zhang P, Wang C, Wang W. Surgical versus non-surgical methods for acute Achilles tendon rupture: a meta-analysis of randomized controlled trials. J Foot Ankle Surg. 2018;57(6):1191-9.

36. Keating JF, Will EM. Operative versus non-operative treatment of acute rupture of tendo Achillis: a prospective randomised evaluation of functional outcome. J Bone Joint Surg (Br). 2011;93(8):1071-8.

37. Lantto I, Heikkinen J, Flinkkila T, Ohtonen P, Siira P, Laine V, et al. A prospective randomized trial comparing surgical and nonsurgical treatments of acute Achilles tendon ruptures. Am J Sports Med. 2016;44(9): 2406-14.

38. Amin NH, Old AB, Tabb LP, Garg R, Toossi N, Cerynik DL. Performance outcomes after repair of complete achilles tendon ruptures in national basketball association players. Am J Sports Med. 2013;41(8):1864-8.

39. Parekh SG, Wray WH 3rd, Brimmo O, Sennett BJ, Wapner KL. Epidemiology and outcomes of Achilles tendon ruptures in the National Football League. Foot Ankle Spec. 2009;2(6):283-6.

40. Ochen $Y$, Beks RB, van Heijl $M$, Hietbrink F, Leenen $L P H$, van der Velde $D$, et al. Operative treatment versus nonoperative treatment of Achilles tendon ruptures: systematic review and meta-analysis. BMJ. 2019;364:k5120.

41. Soroceanu A, Sidhwa F, Aarabi S, Kaufman A, Glazebrook M. Surgical versus nonsurgical treatment of acute Achilles tendon rupture: a meta-analysis of randomized trials. J Bone Joint Surg Am. 2012;94(23):2136-43.

42. Suchak AA, Bostick GP, Beaupre LA, Durand DC, Jomha NM. The influence of early weight-bearing compared with non-weight-bearing after surgical repair of the Achilles tendon. J Bone Joint Surg Am. 2008;90(9):1876-83.

43. Young SW, Patel A, Zhu M, van Dijck S, McNair P, Bevan WP, et al. Weightbearing in the nonoperative treatment of acute Achilles tendon ruptures: a randomized controlled trial. J Bone Joint Surg Am. 2014;96(13):1073-9.

44. Karanicolas PJ, Farrokhyar F, Bhandari M. Practical tips for surgical research: blinding: who, what, when, why, how? Can J Surg. 2010;53(5):345-8

45. Higgins JP, Altman DG, Gotzsche PC, Juni P, Moher D, Oxman AD, et al. The Cochrane Collaboration's tool for assessing risk of bias in randomised trials. BMJ. 2011;343:d5928.

\section{Publisher's Note}

Springer Nature remains neutral with regard to jurisdictional claims in published maps and institutional affiliations.

\section{Ready to submit your research? Choose BMC and benefit from}

- fast, convenient online submission

- thorough peer review by experienced researchers in your field

- rapid publication on acceptance

- support for research data, including large and complex data types

- gold Open Access which fosters wider collaboration and increased citations

- maximum visibility for your research: over $100 \mathrm{M}$ website views per year

At BMC, research is always in progress.

Learn more biomedcentral.com/submissions 